\title{
ANTHOCORIS GOLESTANICUS SP. N. (HEMIPTERA, HETEROPTERA, ANTHOCORIDAE), A NEW SPECIES FROM IRAN
}

\author{
Pierre Moulet $^{1}$, Hassan Ghahari $^{2}$ and Hadi Ostovan ${ }^{3}$ \\ ${ }^{1}$ Museum Requien, 67 rue Joseph Vernet, F-84000 Avignon, France; \\ E-mail: pierre.moulet@mairie-avignon.com \\ ${ }^{2}$ Department of Plant Protection, Yadegar-e-Imam Khomeini (RAH) Shahre Rey Branch, \\ Islamic Azad University, Tehran, Iran; E-mail: hghahari@yahoo.com. Corresponding author \\ ${ }^{3}$ Department of Entomology, Shiraz Branch, Islamic Azad University, Shiraz, Iran; \\ E-mail: ostovan2001@yahoo.com
}

Anthocoris golestanicus sp. n. (Hemiptera: Heteroptera: Anthocoridae) is described from Golestan province (northern Iran). The species was collected on Rubus hyrcanus (Linnaeus) (Rosaceae) as the predator of Aphis idaei van der Goot, 1912 (Hemiptera: Aphididae) and Aleurocanthus zizyphi Priesner et Hosny, 1934 (Hemiptera: Aleyrodidae). Updated list of Iranian Anthocoris is given. With this new species, the total number of Iranian Anthocoris reaches to 16 species.

Key words: Anthocoris golestanicus sp. n., description, distribution, identification key, illustration.

\section{INTRODUCTION}

Anthocoris Fallén, 1814 (Hemiptera: Heteroptera: Anthocoridae) is the second largest genus in the family Anthocoridae, comprising more than 70 species worldwide (KE \& Bu 2007, PÉRICART 2007). The majority of species occur in the Holarctic Region, but the genus is most speciose in Asia (Yamada et al. 2010). Species of the genus Anthocoris are usually found on broad-leaved plants, particularly on trees, where they appear to feed on small insects (especially homopteran and thrips species) and mites. Some species have been known as economically important predators on agricultural pests (LATTIN 2000, HORTON 2008).

While studying new captures of anthocorids or material preserved in several Iranian institutions in updating the existing catalogue of Iranian Anthocoridae (GHahari et al. 2009), we found 3 specimens of Anthocoris which were discovered to belong to a yet unknown species, Anthocoris golestanicus sp. n., described in this paper.

\section{MATERIAL AND METHODS}

Study area - The Golestan National Park is the first and largest area in Iran to be designated as a national park. It is situated in the highlands of the Caspian region, between 
Golestan and Northern Khorasan provinces, at $37.16^{\circ}$ to $37.36^{\circ}$ north latitude and $55.44^{\circ}$ to $56.17^{\circ}$ east longitude (Fig. 1). This park has an area of about 91000 hectares with a wide spectrum of flora and fauna. The terrain is mountainous with altitude varying between 380 and 2819 meters. The park contains a rich diversity of flora and fauna, unique in many respects (Fig. 2) (HAssAn ZADEH et al. 1993).

Specimen preparation - All specimens were killed and preserved in $75 \%$ ethyl alcohol just after collecting. They were then dried and mounted for examination of various structures. Examination and illustration of genitalia and other external structures such as ostiolar peritreme and evaporatorium were made from specimens macerated in $10 \%$ hot $\mathrm{KOH}$ solution for 10 minutes. Specimens were dissected with micro-pins in glycerin on a glass slide beneath a binocular microscope (Leica MZ 12-5). Illustrations were made with use of a binocular microscope and aid of an eyepiece grid.

In addition to description of the new species, the checklist of Iranian Anthocoris is given, and also identification key on the studied specimens is presented. The specimens



Fig. 1. Map of Golestan National Park and neighbouring areas 
of 3 species, Anthocoris angularis Reuter, A. poissoni Kiritshenko and A. simillimus Poppius are not available for the authors because they are preserved in the collection of R. E. Linnavuori which were sent to him by the 2 nd author some years ago. Distribution data are according to Péricart (1996) and Aukema et al. (2013).

\section{RESULTS}

\section{Checklist of Anthocoris species of Iran}

Anthocoris angularis Reuter, 1884 - Distribution in Iran: Tehran (GHAHARI et al. 2009).

General distribution: Central Asia (Kazakhstan, Kirgizia, Mongolia, Tajikistan, Uzbekistan); doubtful in Azerbaijan.

Anthocoris butleri Le Quesne, 1954 - Distribution in Iran: Mazandaran (GHAHARI et al. 2009). General distribution: Western Europe, known to Sweden.

Anthocoris confusus Reuter, 1884 - Distribution in Iran: Golestan, Guilan, Hamadan, Mazandaran (GHahari et al. 2009). General distribution: Palaearctic; also known in North America; in North Africa only cited from Tunisia.

Anthocoris flavipes Reuter, 1884 - Distribution in Iran: Golestan, Kerman, Mazandaran (Ghahari et al. 2009). General distribution: Kazakhstan, China (Xizang, Qinghai), Kirgizia, Tadjikistan, Indian Tibet; doubtful in Armenia.

Anthocoris gallarumulmi (De Geer, 1773) - Distribution in Iran: Golestan, Razavi Khorasan, Semnan (Ghahari et al. 2009). General distribution: West Palaearctic and Caucasus (Armenia, Georgia, Asian Turkey, Azerbaijan).

Anthocoris golestanicus sp. $\mathbf{n}$.

Anthocoris guentheri Péricart, 2007 - Distribution in Iran: Razavi Khorasan (GHAHARi et al. 2009). General distribution: Endemic to Iran.

Anthocoris limbatus Fieber, 1836 - Distribution in Iran: Isfahan (GHAHARi et al. 2009). General distribution: Euro Siberian (incl. NW China).

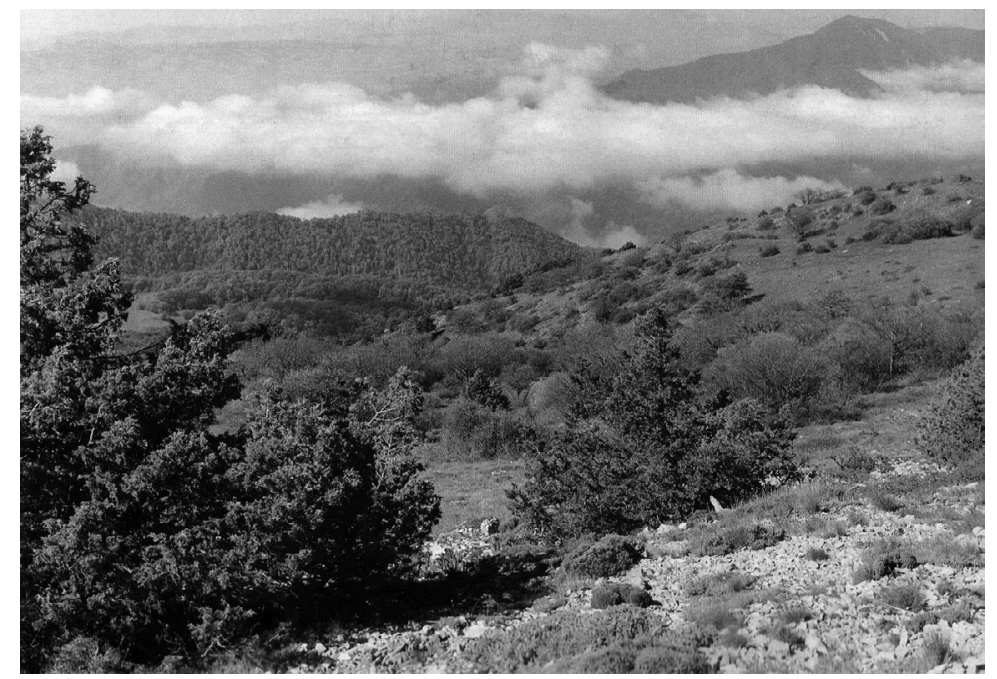

Fig. 2. Landscape of Golestan National Park (adapted from Hassan ZADEH et al. 1993) 
Anthocoris minki minki Dohrn, 1860 - Distribution in Iran: Ardabil, E Azarbaijan, Fars, Golestan, Mazandaran (GHAHARI et al. 2009). General distribution: Europe, but not in Scandinavia.

Anthocoris minki pistaciae Wagner, 1957 - Distribution in Iran: Ardabil, Fars, Kerman, Razavi Khorasan, Sistan \& Baluchestan (GHAhARi et al. 2009). General distribution: Greece (including Cyprus), Near East, southern Russia, Ukraine, Caucasus, Central Asia, Mongolia, north western China.

Anthocoris nemoralis (Fabricius, 1794) - Distribution in Iran: Ardabil, East Azarbaijan, Fars, Golestan, Guilan, Isfahan, Markazi, Mazandaran, Razavi Khorasan, Tehran, Zanjan (GHahari et al. 2009). General distribution: Euroasia, North Africa (incl. Canary Islands), Azores; introduced into Canada and USA.

Anthocoris nemorum (Linnaeus, 1761) - Distribution in Iran: East Azarbaijan, Fars, Golestan, Guilan, Hamadan, Isfahan, Kermanshah, Kordestan, Markazi, Mazandaran, Semnan, Tehran, West Azarbaijan, Yazd, Zanjan (Ghahari et al. 2009). General distribution: Palaearctic, not in North Africa, not cited from Japan. Comment: In the western Palearctic Region, Anthocoris nemoralis and A. nemorum have been well studied as major predators on pear and apple (LATTIN 2000).

Anthocoris pilosus (Jakovlev, 1877) - Distribution in Iran: Ardabil, Fars, Guilan, Mazandaran, Razavi Khorasan, Semnan, Tehran (Ghahari et al. 2009). General distribution: Palaearctic except the far most East (Far East Russia, Korea, Japan) and North Africa.

Anthocoris poissoni Kiritshenko, 1952 - Distribution in Iran: West Azarbaijan (GHAHARi et al. 2009). General distribution: Iran, Kirgizia, Tajikistan.

Anthocoris simillimus Poppius, 1909 - Distribution in Iran: Guilan (GHahari et al. 2009). General distribution: Iran, Kirgizia, Tajikistan.

Anthocoris visci Douglas, 1889 - Distribution in Iran: Kordestan (GHAHARI et al. 2009). General distribution: Western Europe, Spain, Macedonia, Albania, Serbia, Asian Turkey, Iran.

\section{Anthocoris golestanicus sp. $n$.}

(Figs 3-10)

Type material - Holotype: male «Holotype, Anthocoris golestanicus Moulet, Ghahari \& Ostovan spec. nov., P. Moulet det. 2017 [printed, red label] / Dasht e-Mirzabaylu, 8.vi.2011, leg. H. Ghahari, on Rubus hyrcanus [printed, white label]».

Paratypes male and female with the same labels except «Paratype».

Type depository - All type specimens are deposited in Museum Requien, France.

Measurements (in mm) - (1st data: holotype male, 2nd allotype female, 3rd paratype male). Total length: 2.61-2.61-2.43. 1st antennal joint: 0.12-0.135-0.12; 2nd: 0.42-0.3-0.405; 3rd: 0.225-0.255-0.225; 4th: 0.3-0.3-abs. Diatone: 0.39-0.39-0.375. Length of pronotum at the mid line: $0.42-0.42-0.36$. Width of pronotum at humeral angles: $0.84-0.81-0.78$. Length of scutellum: $0.375-0.405-0.39$. Length of profemur: $0.375-0.405-a b s$. Length of protibia: $0.45-0.45-$ abs. Length of mesofemur: $0.39-0.42-$ abs. Length of mesotibia: $0.45-0.495-a b s$. Length of metafemur: 0.525-0.54-0.54. Length of metatibia: $0.57-0.6-0.57$. Abs $=$ absent.

The abdomen and pygophore of the holotype are sticked on the label with the specimen.

Description - Head light brown to reddish brown with sparce short and thin golden setae; 6 macrochetes: 2 between the eye and the base of the clypeus, 2 just behind the ocelli, 2 near the apex of the clypeus. Eyes round not prominent laterally, without setae.

Antennae (Fig. 5), first joint short, cylindrical, yellowish to brown; 2nd the longest, regularly enlarged from base to apex, yellowish with embrowned apex or basal half brown 
and apical half blackish; 3rd fusiform, yellowish, apex embrowned or not, basal third brown and apical two third blackish; 4th elliptic, always blackish. First antennal joint with short and thin white setae at the apex, other joints with golden or light brown setae, some of them recumbent and others semi erect; on 4th joint some setae nearly perpendicular to joint axis. Antennae hardly shorter than the head, pronotum and scutellum together.

Pronotum blackish, anterior collar very thinly transversally striate; anterior calli smooth and shiny; disc - just behind the calli - strongly concave, with thin golden setae directed backwards. Anterior angles nearly absent, little marked. Lateral margins slightly concave at calli level; humeral angles obtuse or rounded; posterior margin regularly concave.

Scutellum triangular blackish with thin golden setae (like those on the pronotum), basal half regularly rounded, apical half flat (Fig. 3).

Hemelytron (Fig. 3), clavus brown more or less dark. Endocorium light brown at the extreme apex, regularly embrowned from apex to base, cuneal region dark brown or blackish; exocorium brown, darkened laterally (reddish or brown) at base or base completely dark brown. Clavus and apex of endocorium until the inner angle of the corium with long strong white and hooked setae (Fig. 4); the rest of the mesocorium (including the cuneus) with short black and erected setae; margin of the base of the exocorium and cuneus with thin light brown setae. Cuneus, base of the corium and basal half of the exocorium very shining; the rest less shining and seeming dull due to the pilosity (strong white setae).

Membrane milky white, smoked posteriorly and also very thinly along the base of the corium (Fig. 3).

Ventral side of the head brown to reddish; rostrum dark brown to blackish.

Pectus dark brown, reddish brown or light brown (in this case propectus orange). Middle of the pectus with thin, recumbent white or golden setae. Mesopleura regularly and thinly striate with some thin setae. Evaporatorium subrectangular (Fig. 10), external angles round; transverse ostiolar peritreme abruptly curved at the end and directed upward continuing in a suture line which does not reach the anterior margin of the metapleura. Coxae and femora yellowish-orange, light brown or reddish; tibiae and tarsi yellowish or pale orange. Setae of femora very thin, semi erect, golden; those on tibiae golden, stronger and more numerous than those on femora, semi erect.

Venter black, reddish or brown (more or less dark). Anterior margin of sternites with stiff white pegs, some on lateral sides shorter; 2nd sternite (Fig. 6) regularly and deeply concave sub medially, internal mid line in a rounded hip; lateral cuticular fold strong.

Paramere lengthily triangular (Figs 7-9), external margin straight or hardly bent (depending upon orientation), apex round or acute, briefly curved.

Differential diagnosis - The paramere of Anthocoris golestanicus sp. n. only matches well with those of the japonicus-group: Anthocoris japonicus Poppius, 1909, A. takahashii Hiura, 1959 and A. ussuriensis Lindberg, 1927 (Bu \& ZHENG 2001). In these three species the paramere is more (ussuriensis and takahashii) or less (japonicus) curved whereas in A. golestanicus sp. n. it is nearly straight or gently bent (Figs $7 \& 8$ ). Anthocoris golestanicus sp. n. differs from other members of the japonicus-group by its antennae hardly shorter than head, pronotum and scutellum together (much shorter in the three other species) and by the long strong white and hooked setae on the clavus and apex of the endocorium. Anthocoris golestanicus sp. $\mathrm{n}$. is the smallest species of the group: $2.43-2.61$ vs 3.4-4.0 $\mathrm{mm}$. 




Figs 3-10. Anthocoris golestianus sp. n.: 3 = upper face (except head) (scale $1 \mathrm{~mm}$ ), $4=$ long strong white hooked setae on clavus and apex of hemelytron (scale $0.3 \mathrm{~mm}$ ), $5=$ antenna (scale $0.25 \mathrm{~mm}$ ), 6 = sternite II (scale $0.25 \mathrm{~mm}$ ), $7-9=$ paramere in different positions (scale $0.06 \mathrm{~mm}$ ), 10 = evaporatorium (scale $0.1 \mathrm{~mm}$ ) 
Etymology - The specific name is after the province (Golestan) where the type material have been collected.

Distribution - All the samples have been collected from Iran, Golestan province, Dasht e-Mirzabaylu, on 8th June of 2011 by H. Ghahari by aspirator and batting Rubus hyrcanus (Linnaeus) (Rosaceae).

Plant association - Rubus hyrcanus (Linnaeus) (Rosaceae)

Biology - Predator of Aphis idaei van der Goot, 1912 (Hemiptera: Aphididae) and Aleurocanthus zizyphi Priesner \& Hosny, 1934 (Hemiptera: Aleyrodidae). A. zizyphi was recorded from Golestan province on Rubus hyrcanus by GHAHARI et al. (2007).

\section{IDENTIFICATION KEY TO THE IRANIAN ANTHOCORIS FALLÉN}

1(8) Antennae nearly as long as the head-pronotum-scutellum together 2

2(3) Yellowish hemelytra (except the cuneus sometimes); yellowish legs; thin and angulate paramere

flavipes Reuter, 1884

3(2) Paramere blade shaped, broad or very broad in the middle, regularly arcuate

4(5) Endocorium with strong white and strongly curvate setae; broad paramere

golestanicus sp. n.

5(4) Endocorium with thin brown or golden erected or gently curvate setae; very broad paramere

6(7) Fully black pronotum nemorum (Linnaeus, 1761)

7(6) Pronotum bicolored, posterior lobe yellow limbatus Fieber, 1836

8(1) Antennae shorter (or much shorter) than head-pronotum-scutellum together

9(16) Paramere dentate sub apically or with a terminal groove 10

10(11) Head short, its apex reaching the middle of the 1st antennal joint; endocorium and clavus dull; only on Viscum album visci Douglas, 1889

11(10) Head longer, its apex reaching the apex of the 1st antennal joint; endocorium and clavus shining; on numerous trees and shrubs 12

12 (15)Paramere with a sub apical tooth

13(14) General coloration dark (dark brown), endocorium and clavus more or less shining; $3.5-4 \mathrm{~mm}$ confusus Reuter, 1884 
14(13) General coloration lighter (tawny yellow, reddish), endocorium and clavus not shining (more or less matt); $2.8-3.2 \mathrm{~mm}$

pistaciae Wagner, 1957

15(12) Paramere with a terminal groove, sometimes with a very indistinct tooth; 3-3.5 mm minki Dohrn, 1860

16(9) Not dentate paramere

17(18) Only on Buxus

butleri Le Quesne, 1954

18(17) On other trees and herbs

19(20) Upper face of the body with long setae forming a fringe overlapping broadly the margins of the pronotum pilosus (Jakovlev, 1877)

20(19) Pilosity of the body shorter or sub glabrous body, lateral fringe of setae short

21(22) Sub glabrous body; pronotum brown yellow, reddish or reddish yellow with (or not) a medio longitudinal black stripe guentheri Péricart, 2007

22(21) Body with a short pilosity; black or dark brown pronotum

23(24) Femora black or dark brown, lighter at base and apex; apex of the paramere hooked sibiricus Reuter, 1875

24(25) Femora reddish or brownish, darkened (or not) at the apex; paramere regularly narrowed from base to apex, not hooked at the apex

25(26) Antennal segment II as long as (or nearly) than the diatone (0.9-1.0 times); maximal length $4 \mathrm{~mm}$ nemoralis (Fabricius, 1794)

26(25) Antennal segment II shorter (0.8-0.85 times) than the diatone; minimal length $4 \mathrm{~mm}$ gallarumulmi (De Geer, 1773)

\section{DISCUSSION}

The results of this paper with 16 species of Anthocoris indicate that there is diverse fauna of Anthocoris in different regions of Iran. Among the the 31 Iranian provinces, only 19 of have been collected systematically. Among them, Golestan and Mazandaran with 7 recorded species have the highest diversity following by Fars, Guilan and Razavi Khorasan provinces with 5 species. These results are biased towards the more sampled provinces. Southern and southwestern parts of Iran have poorly been studied so far and sampling surveys in these regions will result to new findings. Since Iran is a large coun- 
try with various regions and climates, we expect more species of Anthocoris which will be discovered by systematic samplings.

Acknowledgements - The authors are grateful to D. R. Horton, T. M. Lewis (USA) and K. Yamada (Japan) for editing the manuscript and insightful comments. The research was supported by Islamic Azad University (Yadegar-e-Imam Khomeini (RAH) Shahre Rey Branch) and Museum Requien (France).

\section{REFERENCES}

Aukema, B., Rieger, C. \& Rabitsch, W. (2013): Catalogue of the Heteroptera of the Palaearctic Region. Volume 6. Supplements. - The Netherlands Entomological Society, Ponsen \& Looijen, Amsterdam, xxiv + 629 pp.

Bu, W. \& Zheng, L. Y. (2001): Hemiptera Lasiochilidae, Lyctocoridae, Anthocoridae. In: Fauna Sinica, Insecta, vol. 24. - Science Press, Beijing, vii + 267 pp. [in Chinese, keys and descriptions of new species in English]

Ghahari, H., Abd-Rabou, S., Ostovan, H. \& Samin, N. (2007): Whiteflies (Homoptera: Aleyrodidae) and their host plants in Golestan province, Iran. - Plant and Ecosystem 12: 17-28. [in Persian, English summary]

Ghahari, H., Carpintero, D. L. \& Ostovan, H. (2009): An annotated catalogue of the Iranian Anthocoridae (Hemiptera: Heteroptera: Cimicomorpha). - Acta Entomologica Musei Nationalis Pragae 49: 43-58.

Hassan Zadeh, B., Zehzad, B., Farhang, B., Majnounian, H. \& Goshtabs, H. (1993): Golestan National Park. - Department of Environment, Fardin Publication, 203 pp.

Horton, D. R. (2008): Minute pirate bugs (Hemiptera: Anthocoridae). Pp. 2402-2412. In: Capinera, J. L. (ed.): Encyclopedia of Entomology, 2nd ed., Vol. 3. - Springer Science + Business Media B. V., Germany, 4346 pp.

KE, Y.-L. \& BU, W.-J. (2007): Female copulatory tubes and subdivision of the genus Anthocoris (Heteroptera: Anthocoridae: Anthocorini). - European Journal of Entomology 104: 89-98. https://doi.org/10.14411/eje.2007.014

Lattin, J. D. (2000): Chapter 26. Minute pirate bugs (Anthocoridae). Pp. 607-637. In: Schaefer, C. W. \& PAnizzi, A. R. (eds): Heteroptera of economic importance. - CRC Press, Boca Raton, FL, 828 pp. https://doi.org/10.1201/9781420041859.ch26

Pericart, J. (1996): Anthocoridae. Pp. 108-140. In: Aukema, B. \& Rieger, C. (eds): Catalogue of the Heteroptera of the Palaearctic Region. Volume 2. Cimicomorpha I. - The Netherlands Entomological Society, Ponsen-Looijen, Amsterdam, xiv + 361 pp.

Pericart, J. (2007): A new species of Anthocoris from Iran: Anthocoris guentheri n. sp. (Heteroptera: Anthocoridae). Pp. 109-111. In: RenJer, C. (ed.): Festschrift zum 70. Geburtstag von Hannes Günther. - Mainzer Naturwissenschaftliche Archiv, Beiheft 31: 1-339.

Yamada, K., Ballal, C. R., Gupta, T. \& Poorani, J. (2010): Description of a new species of Anthocoris (Hemiptera: Heteroptera: Anthocoridae) from southern India, associated with striped mealybug on purple orchid tree. - Acta Entomologica Musei Nationalis Pragae 50(2): 415-424.

Received April 25, 2017, accepted August 30, 2017, published May 31, 2018 


\title{
The Natural History of Burnet Moths (Zygaena Fabricius, 1775) (Lepidoptera: Zygaenidae), Part 1
}

\author{
Authors: AXEL F. HOFMANN \& W. GERALD TREMEWAN
}

630 pages, 4663 colour \& b/w photos, illustrations, and distribution maps, $\$ 252 / 214$

(order directly from Museum Witt: heike_reichert66@web.de)

This voluminous book is the first part of a monograph series on burnet moths (Zygaena), a pectacular and popular group of diurnal moths that has become one of the most intensively studied models of chemical ecology and evolutionary biology. The book is really the "life work" of two exceptional and passionate researchers, AxEL HOFMANN and W. GERALD TREMEWAN. Unfortunately, the senior author (W.G.T. 1931-2016) died shortly before the appearance of this volume. They performed an enormous field work, often under extremely difficult conditions, from North Africa across Asia Minor, Iran and Afghanistan to the former Soviet Central Asia but also in the Arabian Peninsula and South Africa.

The book clearly exemplifies that the burnet moths are really a "microcosmos" within the Lepidoptera. The moths, but also the larvae, the latter mostly feeding on highly poisonous plants, display some striking contrasty aposematic colouration, e.g. in high altitudes often "metallic" black with glary yellow or orange pattern as e.g. the not closely related Zygaena exulans in the Alps, Z. speciosa in Elburs Mts, and Z. alpherakyi in Daghestan. Not surprisingly, the seemingly sluggish moths with "bloody" colouration (see: "Blutströpfchen" in German, i. e. 'blood drops') were from ancient times popular among naturalists.

This Volume 1 contains a general section and introductory chapters to historical observations on the biology of burnet moths, with detailed remarks on Afrotropical and Oriental Zygaeninae. The laborious survey on this group contains the detailed macro- and micro-morphology of all life stages from batches of ova, fully-grown larvae, pupae and cocoons, and adult moths illustrated in full colours and detail figures, the description of the whole life history illustrated with habitats, host-plants and photos on the behaviour of moths, all reproduced from photographs of living individuals. The reader will be really surprised and enjoyed by the astonishing details and complexity, e.g., from the fine details of scanning micrographs on oxalate crystallites in the cocoons to the large scale phylogeny of the subfamily and genus.

At least equally interesting is the discovery of phylogenetic signals e.g. ovipositing behaviour and in the colouration of cocoon, i.e. in characters of evident adaptive value. A special quality of this really integrative work is that the authors elucidated most details of the burnets' life history with highest precision and immense patience, following the results of crosses in several broods to explain the heredity and variation.

The next richly illustrated chapters include the phylogeny and phylogenetic biogeography of evolutionary lineages of Zygaeninae and Zygaena, including the detailed review of endemism and species diversity core areas. The most important areas are the Iberian Peninsula with the Maghreb, with 31 endemic species; East Anatolia and Iran with 30 endemic species and the Hindukush-Pamir-Western Tien Shan area with 15 endemic species. The Palearctic fauna of Zygaenidae is analysed in details according to the size and shape of area but also according to vertical distribution, macrohabitat type and core area of dispersal. The areal types are depicted in numerous maps of distributions, in most cases also with points of documented occurrences. Examples of sibling species, vicariant taxa, types of disjunctions are also presented, in some cases, e.g. in Zygaena exulans analysing the geographical patterns historically in details. From European littorals to the high mountains of Central Asia, numerous typical and spectacular habitats of Zygaena species are visualised, together with the "inhabitants", on highest quality pictures. The history of research on burnets forms the last part of the book, with many important details on the life and work of entomologists who contributed significantly to our knowledge on Burnet Moths or even devoted their whole life for this passion.

As an appendix of this monumental work, the genital parts of all species are depicted in all details, in high quality drawings.

This book, and the next volumes of the series The Natural History of Burnet Moths should belong to all public and private entomological libraries as firm basis of integrate scientific information, but also as a source of delight in the sense of "Insektenbelustigungen". 